\title{
Treatments for traumatic brain injury with emphasis on transcranial near-infrared laser phototherapy
}

Larry D Morries'

Paolo Cassano ${ }^{2}$

Theodore A Henderson ${ }^{1,3}$

'Neuro-Laser Foundation, Lakewood, CO, ${ }^{2}$ Harvard Medical School, Depression Clinical and Research Program, Massachusetts General Hospital, Boston, MA, ${ }^{3}$ The Synaptic Space, Centennial, CO, USA

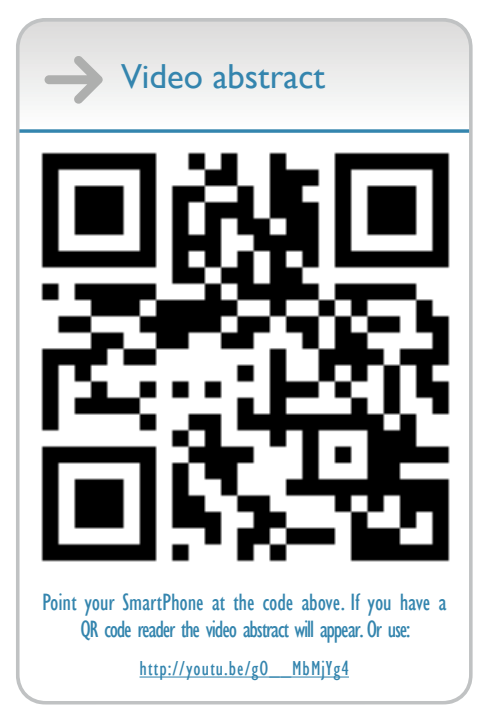

Correspondence: Theodore A Henderson

The Synaptic Space, 3979 East Arapahoe Road, Suite 200, Centennial, CO 801 I2, USA

Tel +I 720493 II0I

$\mathrm{Fax}+\mid 720493$ II07

Email thesynapticspace7@gmail.com
This article was published in the following Dove Press journal:

Neuropsychiatric Disease and Treatment

20 August 2015

Number of times this article has been viewed

Abstract: Traumatic brain injury (TBI) is a growing health concern affecting civilians and military personnel. In this review, treatments for the chronic TBI patient are discussed, including pharmaceuticals, nutraceuticals, cognitive therapy, and hyperbaric oxygen therapy. All available literature suggests a marginal benefit with prolonged treatment courses. An emerging modality of treatment is near-infrared (NIR) light, which has benefit in animal models of stroke, spinal cord injury, optic nerve injury, and TBI, and in human trials for stroke and TBI. The extant literature is confounded by variable degrees of efficacy and a bewildering array of treatment parameters. Some data indicate that diodes emitting low-level NIR energy often have failed to demonstrate therapeutic efficacy, perhaps due to failing to deliver sufficient radiant energy to the necessary depth. As part of this review, we present a retrospective case series using high-power NIR laser phototherapy with a Class IV laser to treat TBI. We demonstrate greater clinical efficacy with higher fluence, in contrast to the bimodal model of efficacy previously proposed. In ten patients with chronic TBI (average time since injury 9.3 years) given ten treatments over the course of 2 months using a high-power NIR laser $\left(13.2 \mathrm{~W} / 0.89 \mathrm{~cm}^{2}\right.$ at $810 \mathrm{~nm}$ or $9 \mathrm{~W} / 0.89 \mathrm{~cm}^{2}$ at $810 \mathrm{~nm}$ and $980 \mathrm{~nm}$ ), symptoms of headache, sleep disturbance, cognition, mood dysregulation, anxiety, and irritability improved. Symptoms were monitored by depression scales and a novel patient diary system specifically designed for this study. NIR light in the power range of 10-15 W at $810 \mathrm{~nm}$ and $980 \mathrm{~nm}$ can safely and effectively treat chronic symptoms of TBI. The clinical benefit and effects of infrared phototherapy on mitochondrial function and secondary molecular events are discussed in the context of adequate radiant energy penetration.

Keywords: infrared, traumatic brain injury, TBI, transcranial infrared light therapy, transcranial laser therapy

\section{Introduction}

Traumatic brain injury (TBI) has recently moved into the limelight due to the recognition of its impact on professional athletes and military personnel. Yet, TBI is neither a new problem nor limited to those two populations. The Centers for Disease Control and Prevention estimated that 1.5 million Americans sustained TBI annually in $2000 .{ }^{1}$ As of 2006 , the estimates had risen to 1.7 million brain injuries annually. ${ }^{2,3}$ Undoubtedly, these point prevalence proportions will increase as military personnel return home, ${ }^{4}$ and the problem of repeated mild TBI (mTBI) becomes more recognized in sports. ${ }^{5}$ Current estimates of the prevalence of TBI among veterans range from $9.6 \%{ }^{6}$ to $20 \%$, ${ }^{7}$ with an estimated total of more than 300,000 cases of TBI among military personnel since 2000. ${ }^{4}$ The current estimates of the combined number of sports-related concussions and brain injuries in the US are 1.6-3.8 million annually. ${ }^{8-10}$ 
TBI results in a wide spectrum of neurological, psychiatric, cognitive, and emotional consequences. In part, the variation is related to the severity of the injury (mild, moderate, severe TBI), which is stratified based on Glasgow Coma score, periods of unconsciousness, and degrees of amnesia. Furthermore, the diversity of sequalae can be related to the areas of the brain that are injured, the severity of the injury (highly variable within the classification of "mild" and "moderate"), and the evolution of the injury over time due to neuroinflammatory processes. ${ }^{11,12}$ Additional mechanisms thought to underlie the damage of TBI include decreased mitochondrial function, calcium and magnesium dysregulation, excitotoxicity, disruption of neural networks, free radical-induced damage, excessive nitric oxide, ischemia, and damage to the blood-brain barrier. Together, these can contribute to a progression of the damage over time.

Patients with TBI can experience headache, visual disturbances, dizziness, cognitive impairment, loss of executive skills, memory impairment, fatigue, impulsivity, impaired judgment, emotional outbursts, anxiety, and depression..$^{3,13-23}$ The situation can be further clouded by secondary and/or comorbid posttraumatic stress disorder (PTSD), depression, and anxiety, ${ }^{17-25}$ which can have symptoms that overlap with those described above and appear to be increasingly likely with repetitive concussive or subconcussive brain injury. $5,24,26$

\section{Treatments for TBI Pharmacological treatments}

Pharmacological treatment largely targets the neuropsychiatric sequalae of TBI, rather than providing any means of healing or repairing injury. In general, pharmacological treatment is focused on the modulation of major neurotransmitter systems - dopaminergic, serotonergic, noradrenergic, acetylcholinergic, and glutaminergic. ${ }^{20}$ Disruption of the major neurotransmitter pathways may result from direct injury or excitotoxicity and other cytotoxic mechanisms.

The treatment of depression secondary to TBI is often approached with serotonin reuptake inhibitors. Several studies have examined the benefit of sertraline in post-TBI depression. ${ }^{27-29}$ Other serotonin reuptake inhibitors also have been examined. Tricyclic antidepressants appear to have some use in the treatment of post-TBI depression, although cautious dose titration is required. Patients with TBI are at greater vulnerability to sedation and cholinergic side effects of confusion and memory impairment. With serotonergic agents other than sertraline, cognitive effects also have been reported..$^{30}$ Similarly, lithium may be a less desirable agent in this population due to sedation and cognitive impairment.
Patients with TBI may respond at lower doses and lower blood levels than expected.

Modulation of the dopaminergic system may improve alertness, attention, and cognitive processing speed. The stimulants are most commonly used for this purpose. Methylphenidate facilitates the release of dopamine and slows its reuptake. Dextroamphetamine strongly inhibits reuptake of dopamine, slows down the breakdown of dopamine by monoamine oxidase, and somewhat increases the release of dopamine. These subtle differences are sometimes imperceptible to the patient, but at other times, a patient will do best on one or the other stimulant. Increasing dopamine in the reticular activating system leads to enhanced arousal. Increasing dopamine within the frontal cortex and the striatum leads to enhanced processing speed and attention. Some evidence suggests that the stimulants may enhance neuronal recovery after injury. ${ }^{31-33}$ There are numerous potential side effects with stimulants, including abnormal heart rhythms, decreased seizure threshold, and death, but these severe side effects are extremely rare. The most common side effects with stimulants are decreased appetite, stomach upset, and headache. These are most severe at the beginning of treatment and improve over time for most patients. Insomnia is another common side effect, which may be more frequent in those with a TBI. Amantadine and bromocriptine may also increase dopamine. Studies of these agents have shown reduced abulia, anergia, and anhedonia in those with TBI. ${ }^{34,35}$ Amantadine may cause confusion, hallucinations, and hypotension. Small studies have suggested some benefits of bromocriptine in cognitive function. ${ }^{36,37}$

Arousal-enhancing agents also have found a use in the treatment of the neurocognitive sequalae of TBI. Modafinil is the oldest form of these medications, and armodafinil is an isomer of modafinil with longer activity and less side effects. These medications help to increase alertness and wakefulness. The precise mechanism of action of modafinil is unclear. It appears to increase histamine in parts of the brain involved in controlling the sleep-wake cycle; however, knock-out mice that lack histamine receptors still show increased wakefulness with modafinil. ${ }^{38,39}$ The picture is also murky for modafinil's effect on orexins, which are wakefulness molecules in the hypothalamus. ${ }^{40}$ Modafinil has been shown to weakly bind to the dopamine transporterlike the stimulants ${ }^{41}$ and dopamine transporter knock-out mice show no response to modafinil. ${ }^{42}$ A number of research studies have examined the benefit of these agents in fatigue associated with multiple sclerosis, TBI, cancer, and other conditions. 
Cognitive and memory impairments after TBI may reflect disruption of cholinergic function. The impact of anticholinergic agents on cognitive function of those with TBI supports this contention. Donepezil is the safest and most widely used of the cholinesterase inhibitors. Several reasonably large studies have shown improved memory and cognitive function. ${ }^{43-45}$ Donepezil has benefits in memory and cognition even several years after injury. ${ }^{45,46}$

Anticonvulsants are often prescribed initially after a TBI due to heightened risk for seizures. Post-TBI mania or mood lability may respond well to anticonvulsants, such as carbamazepine or sodium valproate. They are also often used to treat aggression after TBI. The anticonvulsant agent, topiramate, has been shown to adversely affect cognitive function in the TBI patients. ${ }^{47}$

While insomnia is a significant issue for patients with TBI, affecting between $15 \%$ and $84 \%$ (mean of $40 \%$ ), ${ }^{3,13,19,21,23,48,49}$ little has been published on the treatment of this aspect of TBI. Benzodiazepines may be effective but carry a risk of disinhibition. Kemp et $\mathrm{a}^{48}$ found that commonly used sleep aid, melatonin, was not effective. Antidepressants, including serotonin reuptake inhibitors and tricyclic antidepressants, are not effective in resolving insomnia in this population..$^{49}$ No single agent has emerged as a good solution for this symptom.

\section{Cognitive rehabilitation}

Cognitive rehabilitation now takes many forms and is often individualized to the particular needs of the patients. Protocols have been devised to remediate cognitive difficulties often encountered in those with TBI, such as impaired concentration, executive dysfunction, inattention, visual disturbances, memory dysfunction, and impaired language function. They range from simple strategies (using a planner to aid memory and organization) to specific protocols targeting particular cognitive functions (eg, short-term memory) that can be monitored with sequential neuropsychological testing. These interventions have been extensively reviewed elsewhere. ${ }^{50,51}$ Comprehensive programs which include psychotherapy and social skills components have been shown to have greater efficacy. ${ }^{50,52,53}$ Overall, reports of benefits have been mixed. ${ }^{54,55}$

\section{Behavioral therapies}

Behavioral remediation strategies to eliminate problematic behaviors following TBI have met with mixed success, most often in terms of the poor generalization of specific skills to the outside world. Behavioral deficits that create difficulties for those with TBI and their families include poor hygiene, decline in tidying/cleaning habits, social withdrawal, reduced social comprehension, impaired memory, and poor organization. Behavioral excesses that create difficulties for those with TBI and their families include aggression, sleep disruption, and perseverations. These have been reviewed elsewhere. ${ }^{56}$

\section{Nutritional supplements}

Nutritional supplements, herbs, and nootropics have been utilized for many years and are increasingly popular among the patient populations. There remains little clinical research on many of these agents, perhaps reflecting a lack of funding more than a lack of efficacy. Acetyl-L-carnitine is an ester of L-carnitine and is thought to protect brain cells after injury when glucose metabolic pathways are compromised. During this period, acetyl-L-carnitine supports alternative ketogenic pathways for metabolism. ${ }^{57}$ It is also believed to enhance cholinergic function. While there are several clinical studies on patients with Alzheimer's disease and preclinical data on animal models of TBI, the clinical literature on TBI remains sparse. Ginkgo biloba is a natural product of the tree by the same name. It has been shown to improve membrane fluidity and increase resistance to free-radical damage. It provides some subtle benefits to cognitive function in clinical studies of stroke, dementia, aging, and hypoxia damage. ${ }^{58}$ It has not been systematically studied in TBI but is used extensively in clinic, often in combination with meclofenoxate which is an avid scavenger of free radicals. ${ }^{59} S$-Adenosylmethionine (SAMe) is a nutritional supplement which improves cell membrane fluidity and promotes the production of glutathione, an antioxidant. The benefit of SAMe has been assessed in a single clinical study of TBI. ${ }^{60}$ Patients receiving SAMe had a $77 \%$ improvement in clinical scores of post-concussive symptoms. Citicholine provides a source of choline which can cross the blood-brain barrier. It has been used extensively in Europe and Japan as a treatment for TBI, stroke, and dementia. However, two large US studies failed to demonstrate significant benefit. ${ }^{61,62}$

Piracetam and the related oxiracetam and phenylpiracetam have shown some promise as nootropic agents. In one double-blind, placebo-controlled study, piracetam improved several symptoms of post-concussive syndrome, including headache and vertigo. ${ }^{63}$ More recent clinical studies have shown marginal benefit. ${ }^{64}$ Huperzine-A, an extract of Japanese club moss, is a natural acetylcholinesterase inhibitor. It may serve as a natural alternative to donepezil, rivastigmine, or galantamine. Galantamine warrants special mention as it appears to also modulate nicotinic receptors and appears to have more persistent benefit in the treatment of Alzheimer's disease. It appears to modulate neuroimmune responses, 
in addition to its effects on acetylcholinesterase ${ }^{65}$ Cerebrolysin is a polypeptide that purportedly mimics the actions of neurotrophic factors. ${ }^{66,67}$ Studies have shown that it can reduce beta amyloid and phosphorylated tau protein accumulation. It may promote neurogenesis, synapse formation, and functional recovery. ${ }^{66}$ In animal models of acute TBI, cerebrolysin-treated rats had more surviving neurons in the area of impact and showed greater functional recovery. ${ }^{67}$ In a clinical trial of acute TBI, patients were recruited within 24 hours of injury and treated for 3 months with daily intravenous infusion of cerebrolysin. At 3 months, those receiving cerebrolysin performed significantly better on the Cognitive Abilities Screening Instrument. ${ }^{68}$ It remains unclear if cerebrolysin provides long-term nootropic benefit.

The elevation of free radicals in TBI suggests that antioxidants should be beneficial. Clinical trials of pharmacological antioxidants over the past 30 years have not yielded a useful agent in acute TBI. ${ }^{69}$ Agents, such as tirilazad ${ }^{70}$ and polyethylene glycol-conjugated superoxide dismutase, have failed to show benefit in acute TBI. Omega-3 fatty acids may enhance brain repair and recovery, based on animal and clinical studies. ${ }^{71}$ Similarly, vitamin D may offer neuroprotective and restorative benefits ${ }^{72}$ in the acute TBI setting. In chronic TBI, vitamin D and omega-3 fatty acids may work synergistically, as they both may reduce neuroinflammation, apoptosis, and oxidative stress. ${ }^{73}$ Other nutritional supplements have been recommended, but prolonged therapy is necessary to possibly see benefits in TBI. A 6-month trial of ginkgo, vinpocetine, acetyl-L-carnitine, huperzine, alpha-lipoic acid, $n$-acetyl-cysteine, multivitamins, and over $5 \mathrm{~g}$ of omega-3 fatty acids daily yielded improved performance in cognitive testing and increased perfusion (function) in single-photon emission computed tomography (SPECT) scan. ${ }^{74}$ Long-term use of dietary flavanols may improve cognition in mTBI. ${ }^{75}$

\section{Transcranial magnetic stimulation}

Transcranial magnetic stimulation (TMS) has shown some promise in animal models of TBI. ${ }^{76}$ However, a Cochrane review of the clinical application of TMS for depression noted no difference between repetitive TMS (rTMS) and sham rTMS using the Beck Depression Inventory (BDI) or the Hamilton Depression Rating Scale, except during the initial 2-week period. ${ }^{77}$ The application of TMS in the postTBI patients is limited by the risk of seizure induction. ${ }^{78}$

\section{Hyperbaric oxygen}

Hyperbaric oxygen treatment has been explored as a treatment for TBI. ${ }^{79-91}$ Hyperbaric oxygen therapy is neither a benign treatment, given the concerns of oxygen toxicity, ${ }^{79}$ nor a clear treatment in that the placebo condition of moderate hyperbaric room air also effectively improves cognitive function. ${ }^{80,81}$ The most carefully performed study compared a group in a cross-over design with an interval of both null treatment and hyperbaric oxygen at 100\% oxygen and 1.5 atm. ${ }^{82}$ The study described improvement in many of the symptoms associated with persistent TBI including headache, tinnitus, vision disturbance, memory dysfunction, and impaired cognitive function. Cognitive testing also showed improvement in attention, information processing speed, and a battery of cognitive tests. In an uncontrolled case series of 16 subjects, Harch et $\mathrm{al}^{83}$ demonstrated that an abbreviated series of hyperbaric treatments using $100 \%$ oxygen at $1.5 \mathrm{~atm}$ could mitigate subjective symptoms of TBI (eg, headache, sleep disruption, irritability), improve cognitive testing scores, and improve cortical function based on SPECT imaging. ${ }^{83}$ A study of a higher dose (2.4 atm) did not reveal any significant benefit of hyperbaric oxygen therapy compared to a sham-control group treated with $1.3 \mathrm{~atm},{ }^{84}$ and this result has been extended and confirmed by a related group. ${ }^{85}$ However, this may reflect an inverse dose-response curve, rather than an absence of benefit, in that the low-dose sham group demonstrated significant changes in cognitive testing and symptom frequency. ${ }^{86}$ Hyperbaric oxygen remains a controversial area in both acute $\mathrm{TBI}^{86-89}$ and chronic TBI. ${ }^{82,83,85,86,90,91}$

\section{Physical exercise}

High-energy activities and exercise programs completed through a health club facility or comprehensive rehabilitation program should focus on the same parameters of an age-adjusted and diagnosis-specific program for aerobic conditioning - flexibility, stabilization, and strength. Though it appears safe and is an accepted intervention for TBI, there is a need for further well-designed studies. ${ }^{92}$ Exercise was a part of a 6-month study of lifestyle changes described above which yielded improved function based on cognitive testing and perfusion SPECT scans. ${ }^{74}$

\section{A new treatment for TBI}

Unfortunately, little has been found to reverse the damage of TBI or repetitive concussion which is the root cause of residual cognitive and psychological impairment following TBI. ${ }^{20,93}$ One potential avenue of treatment for TBI is infrared light, which has shown promising data in a number of applications. Near-infrared (NIR) light has been investigated for its ability to modulate intracellular mechanisms related to healing. The application of NIR light by low-power laser or by light-emitting diode (LED) is also known as laser 
phototherapy ${ }^{94}$ or near-infrared photobiomodulation.${ }^{92}$ NIR irradiation can facilitate wound healing, ${ }^{95,96}$ promote muscle repair, ${ }^{95}$ and stimulate angiogenesis. ${ }^{95,96}$ NIR phototherapy has been studied and applied clinically in a wide array of ailments, including skin ulcers, ${ }^{97}$ osteoarthritis, ${ }^{98}$ peripheral nerve injury, ${ }^{95,96}$ low back pain, ${ }^{99}$ myocardial infarction, ${ }^{100}$ and stem cell induction. ${ }^{101}$

The finding that NIR light passes relatively efficiently through bone has spurred interest in its application to treating disorders of the brain. Over the past decade, transcranial near-infrared light therapy (NILT) ${ }^{102}$ has been studied in animal models to understand its ability to repair damaged or dysfunctional brain tissue resulting from stroke and TBI. The first published study of NILT for TBI in humans described two cases of chronic mTBI with significant disability. ${ }^{103}$ Each patient was treated with an LED device delivering low-level low-level light therapy (LLLT) in the red and NIR range for 6-10 minutes per area daily for several months. Both patients had marked neuropsychological improvement after a minimum of 7-9 months of LLLT treatment.

The precise mechanisms underlying photobiomodulation and its therapeutic benefits are not fully understood.
The purported effects of NIR are illustrated in Figure 1. Light in the wavelength range of $600-1,200 \mathrm{~nm}$ has significant photobiomodulation capability. ${ }^{104}$ Current data most strongly support that absorption of NIR photons by cytochrome $\mathrm{c}$ oxidase in the mitochondrial respiratory chain is the key initiating event in photobiomodulation..$^{95,96,104,105}$ This induces an increase in cytochrome $\mathrm{c}$ oxidase activity which in turn increases adenosine triphosphate (ATP) production. Such an increase in ATP in wounded or underperfused cells may be sufficient to activate cells in areas of injury or metabolic derangement. ${ }^{106}$ Data from numerous tissue culture and animal studies point to the importance of several secondary molecular and cellular events. For example, NIR photonic energy can modulate reactive oxygen species, ${ }^{95,96,102}$ activate mitochondrial DNA replication, ${ }^{95,96}$ increase early-response genes, ${ }^{95}$ increase growth factor expression, induce cell proliferation, and alter nitric oxide levels..$^{95,96,102}$ These mechanisms are more fully described in the companion paper. ${ }^{105}$

When examined in the specific model of neural tissue injury, NIR phototherapy can lead to demonstrable neural repair and recovery. For example, LLLT of a power density of $0.9-36 \mathrm{~J} / \mathrm{cm}^{2}$ applied at 24 hours poststroke in a rodent

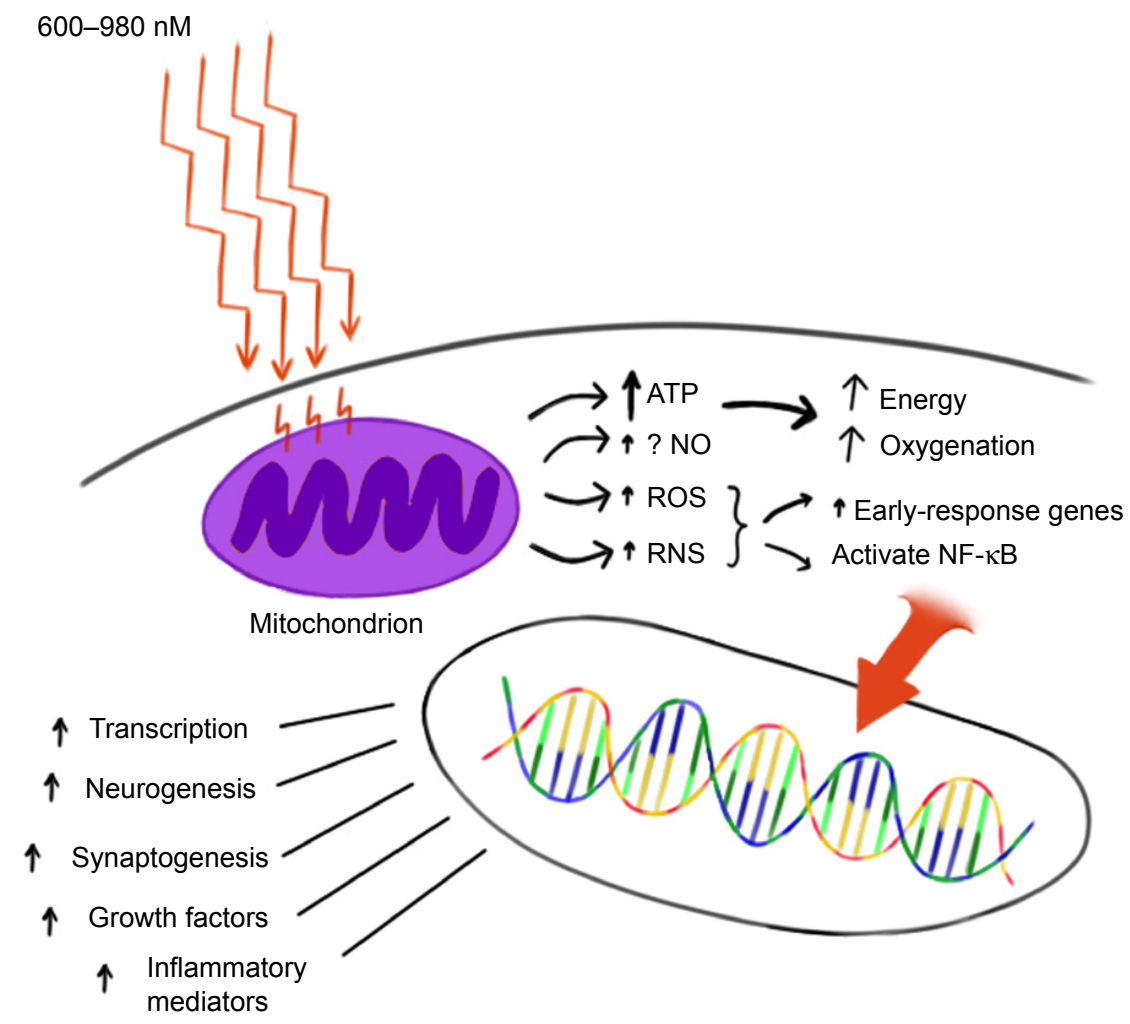

Figure I Hypothesized mechanism of action of NIR light therapy.

Notes: NIR light $(600-980 \mathrm{~nm})$ penetrates tissue to variable depths depending on wavelength, the tissue involved, coherence, and time. A fraction of the photonic energy reaches the mitochondria and is absorbed by cytochrome c oxidase. This activates increased ATP production, increases production of ROS and RNS, and possibly increases NO. Downstream events include increased early-response genes ( $c$-fos and c-jun) and activation of NF- KB, which in turn induces increased transcription of gene products leading to synaptogenesis, neurogenesis, and increased production of inflammatory mediators and growth factors.

Abbreviations: NIR, near-infrared; ATP, adenosine triphosphate; ROS, reactive oxygen species; RNS, reactive nitrogen species; NO, nitric oxide; NF- $\mathrm{KB}$, nuclear factor kappa B. 
model yielded a $32 \%$ reduction in neurological deficits, as well as histochemical evidence of neuron proliferation and migration. ${ }^{106-108}$ LLLT had similar benefits in a rodent model of TBI. ${ }^{96,109-111}$ Interestingly, these cellular changes evolved over a period of days after light exposure and persisted for considerably longer than the interval of actual NIR exposure. These findings are consistent with a progressive regeneration cascade set in motion by the NIR light exposure.

\section{NILT in stroke}

NILT, predominately in the form of LLLT, has been investigated in laboratory models of stroke. LLLT applied in a single dose to an ischemic stroke model appeared to induce expression of the growth factor transforming growth factorbeta 1 and suppress the production of peroxynitrite. ${ }^{112}$ In a rat model of middle cerebral artery occlusion, LLLT at a dose of $0.5-7.5 \mathrm{~mW} / \mathrm{cm}^{2}$ using continuous wavelength light at $808 \mathrm{~nm}$ was administered at 24 hours after the acute stroke. ${ }^{108,113}$ This single application was estimated to deliver $1.8 \mathrm{~J} / \mathrm{cm}^{2}$ in total to the cortex surface and resulted in demonstrable neurological improvement. Functional changes were not manifested until approximately 2 weeks after the single treatment. While there was no significant change in the size of the stroke lesion, histochemical evidence of neurogenesis and migrating neurons ${ }^{108}$ indicate that a cascade of secondary processes was initiated by NILT. A rabbit model of stroke utilizing injection of a blood clot embolus also demonstrated benefit from LLLT. ${ }^{102,114,115}$ Herein, $808 \mathrm{~nm}$ light was applied with an LED delivering $7.5 \mathrm{~mW} / \mathrm{cm}^{2}$ and an estimated 0.9 $2.6 \mathrm{~J} / \mathrm{cm}^{2}$ to the cortical surface. Cortical ATP levels were increased, indicative of increased mitochondrial activity. ${ }^{114}$ Significant behavioral recovery was also noted; however, neither ATP increased nor neurological function changed at doses less than $0.3-0.7 \mathrm{~J} / \mathrm{cm}^{2} .{ }^{114,115}$ At higher doses of $0.9-15 \mathrm{~J} / \mathrm{cm}^{2}$, neurological improvement was seen. ${ }^{114,115}$

The clinical trials of NILT in acute stroke, the NeuroThera Effectiveness and Safety Trials 1, 2, and 3 (NEST-1, -2, -3), were conducted between 2006 and 2009. The Phase II clinical trial (NEST-1) involved 120 patients in a doubleblind, placebo-controlled study of the effects of NILT within 24 hours of ischemic stroke. ${ }^{116,117}$ Approximately $60 \%$ of the patients experienced clinical benefit, and the safety profile was very good. Thus, NEST-2, a Phase III clinical trial, was undertaken in 2007. A total of 660 patients were enrolled. ${ }^{118}$ Somewhat surprisingly, the study did not demonstrate statistical clinical improvement using a different outcome measure. ${ }^{119}$ Post hoc analysis revealed that a portion of the patients who were moderately affected and/or had strokes limited to the cerebral cortex did realize clinically and statistically significant improvement. ${ }^{102}$ The NEST-3 trial was halted midpoint when it failed to demonstrate statistical benefit on futility analysis. ${ }^{120}$

A key factor in the interpretation of the results of NEST-3 is that, different from NEST-1, all types of stroke were included as opposed to just cortical strokes. Continuous laser light has a limited depth of penetration $(\leq 1 \mathrm{~cm}$ into brain tissue) which likely prevents an effect on deeper brain matter. Therefore, the lack of significant benefits from NIR phototherapy in NEST-3 could be related to the fact that ischemic penumbra was not reached by the light (Luis DeTaboada, personal communication, January 2015). While pulsed NIR was not used in the NEST-3 study, it is estimated that pulsed NIR could penetrate up to $3 \mathrm{~cm}$ in depth from the cortical surface, therefore possibly extending the therapeutic target to deeper strokes (Luis DeTaboada, personal communication, January 2015).

\section{NILT in TBI}

Oron et $\mathrm{al}^{109}$ conducted the first animal studies of NILT for TBI. They found that a single application of NIR light at $808 \mathrm{~nm}$ from a $200 \mathrm{~mW}$ emitter at 4 hours post-injury resulted in a significant reduction in lesion size by 5 days. ${ }^{109}$ To date, several groups have studied NILT in animal models, and this material has previously been reviewed..$^{95,121-123}$ Single applications of $800-810 \mathrm{~nm}$ NIR light within 4 hours of injury have been shown to improve neurological function significantly. ${ }^{110,124-126}$ The same dose of NIR light at 6 hours was less effective ${ }^{125}$ and at 8 hours had no appreciable benefit. ${ }^{125}$ NIR photonic energy at other wavelengths was less effective. Wu et al ${ }^{110}$ examined red light $(670 \mathrm{~nm})$ at 4 hours and found a similar improvement in neurological function; however, $730 \mathrm{~nm}$ and $980 \mathrm{~nm}$ had no neurological benefit. Similar data for lesion volume have been reported. A single dose of 800-810 nm NIR light (fluence of $36 \mathrm{~J} / \mathrm{cm}^{2}$ ) yielded an approximate $50 \%$ reduction in the volume of the lesion at 3-4 weeks ${ }^{110,111,124-126}$ and a possible reduction in the initial spread of neurological injury, based on the marked reduction in lesion volume found at 5 days post-injury. ${ }^{109}$

Repeated NIR phototherapy treatments appear to have some benefit, but the frequency and number of treatments are critical factors. While a single NIR light application had benefit, daily applications for 3 days yielded much greater neurological benefit ${ }^{126,127}$ with smaller lesion size, ${ }^{126}$ fewer degenerating neurons, ${ }^{126}$ more proliferating cells, ${ }^{126}$ and greater levels of brain-derived neurotrophic factor (BDNF) $)^{127}$ compared to a single treatment in a mouse model. In contrast, daily treatment for 7 days ${ }^{128}$ or 14 days ${ }^{126}$ showed no difference from controls. NIR energy densities in the range 
of $0.9-36 \mathrm{~J} / \mathrm{cm}^{2}$ resulted in significant biochemical and behavioral changes. ${ }^{109-111,124-127}$

Pulsing of NIR light appears to yield a greater neurological response but only within certain parameters. Pulsing at $10 \mathrm{~Hz}$ yielded greater neurological improvement and a significant reduction in lesion size compared to either continuous-wave or pulsed NIR at $100 \mathrm{~Hz} \cdot{ }^{111}$ In the mouse model of moderate TBI, NILT (800-810 nm) improved learning and memory (Morris water maze performance), ${ }^{128}$ as well as behaviors associated with depression and anxiety (immobility during tail suspension). ${ }^{111,124}$

The finding that NILT brought about a smaller lesion in the rodent model of TBI compared to untreated mice suggests that decreased apoptosis, reduced spreading lesion penumbra, and/or neurogenesis are induced by NILT. Indeed, NILT can decrease $B A X$ expression, a pro-apoptosis gene, ${ }^{129}$ increase expression of $B C L-2$, an anti-apoptosis gene, ${ }^{129}$ increase nerve growth factor, ${ }^{95}$ increase BDNF, ${ }^{127}$ decrease inflammatory markers, ${ }^{130}$ and decrease numbers of degenerating neurons. ${ }^{126}$ Together, these mechanisms may reduce the enlargement of the initial lesion during the first day following the lesion. ${ }^{109}$ Moreover, increased BDNF and nerve growth factor may contribute to synaptogenesis as shown by increased levels of synapsin- $1,{ }^{127}$ and neurogenesis, as shown by increased numbers of proliferating cells. ${ }^{127}$

In a double-blind study in healthy volunteers, NILT was beneficial - compared to sham - in memory and attention. ${ }^{131}$ In this study, the authors shed only one application of NIR light to the right forehead, targeting the right frontal pole of the cerebral cortex (Brodmann's area 9 and 10). The device was a Class IV laser CG-5000 (Cell Gen Therapeutics, Dallas, TX, USA), and the parameters were as follows: wavelength $1,064 \mathrm{~nm}$, irradiance $250 \mathrm{~mW} / \mathrm{cm}^{2}$, fluence $60 \mathrm{~J} / \mathrm{cm}^{2}$, and time 4 minutes per site (two sites). ${ }^{131}$ The subjects who received the NIR treatment had better attention after 2 weeks, measured by the psychomotor vigilance test. They also had better delayed visual memory at the Delayed Match-to-Sample test. This is the only published controlled trial assessing the impact of NILT on cognition; however, other reports have shown the therapeutic effects of NILT in small numbers of TBI patients.

In a two-case report in TBI patients, ${ }^{103}$ NILT $(870 \mathrm{~nm})$ improved sustained attention, memory, and executive functions. Both patients were treated with an instrument with three separate LED cluster heads. The parameters used for the treatment were the following: NIR wavelength $870 \mathrm{~nm}$ and $633 \mathrm{~nm}$ (red light), irradiance $22.2-25.8 \mathrm{~mW} / \mathrm{cm}^{2}$, fluence $13.3 \mathrm{~J} / \mathrm{cm}^{2}$, and time 10 minutes per site. ${ }^{103}$

The same group reported on a cohort of eleven subjects with persistent cognitive dysfunction and treated with a similar NILT protocol for chronic mTBI. ${ }^{132}$ The eleven subjects received NILT with a device with three LED cluster heads (Model 1100; MedX Health, Toronto, ON, Canada). The parameters used for the treatment were the following: NIR wavelength $870 \mathrm{~nm}$ and $633 \mathrm{~nm}$ (red light), irradiance $22.2 \mathrm{~mW} / \mathrm{cm}^{2}$, fluence $13 \mathrm{~J} / \mathrm{cm}^{2}$, and approximate time 10 minutes per site. The NIR light was applied three times per week for 6 weeks (18 sessions), on eleven sites for 10 minutes per site (the total duration of each session was 20 minutes). ${ }^{132}$ The sites on the skull were chosen on the midline, and bilaterally on frontal, parietal, and temporal areas. At the follow-up neuropsychological testing, NILT had a powerful effect on attention, inhibition, and inhibition switching in the Stroop task, and similarly improved verbal learning and memory, as well as enhanced long-delay free recall on the California Verbal Learning Test.

Eight subjects, from the same cohort, were identified as having mild, moderate, or severe depression based on the BDI-II total score (range: $15-34$ ). ${ }^{132}$ The three cases, who entered the study with only mild depression, remained the same after NILT treatment. Results for the five cases with moderate-severe depression were as follows: two moderate cases improved to mild/minimal depression 8 weeks after the end of NILT series, and one severe case improved to moderate depression. Two moderate or severe depression cases remained the same after 8 weeks of follow-up from the last NILT session. ${ }^{132}$

\section{Dose response and photonic penetration}

A prevailing theory in photobiomodulation postulates that a bimodal response curve exists for the biological effects of NIR light. ${ }^{95}$ The so-called Arndt-Schulz curve (a fundamental principle in homeopathic medicine) is frequently used to describe this biphasic dose response. Some data indicate that low levels of light have a much better effect on stimulating and repairing tissues than higher levels of light. Laboratory studies of cells in culture have demonstrated a bimodal dose response to light exposure in lymphocytes ${ }^{133}$ and fibroblasts. ${ }^{134,135}$ For example, Chen et a ${ }^{135}$ found that a range of $0.03-0.3 \mathrm{~J} / \mathrm{cm}^{2}$ was beneficial in activating transcription factors in culture, while $3-30 \mathrm{~J} / \mathrm{cm}^{2}$ inhibited the activation of these factors. In contrast, an order-of-magnitude greater dose $\left(2 \mathrm{~J} / \mathrm{cm}^{2}\right)$ was best at activating fibroblasts in a superficial wound model. ${ }^{136}$ Furthermore, an order-ofmagnitude greater dose $\left(30 \mathrm{~J} / \mathrm{cm}^{2}\right)$ proved to be best in a rodent joint inflammation model. ${ }^{137}$ Thus, a dose-dependent effect for many biological responses to NIR light has been demonstrated, ${ }^{95,137-139}$ but the critical parameter is dose at the 
level of the target tissue, rather than at the surface. ${ }^{137,140}$ The amount of energy that reaches a volume of tissue at depth is determined by the attenuation of the photonic energy as it passes through the overlying tissue. For example, only $2.45 \%$ of the energy from a $980 \mathrm{~nm}$ laser emitter penetrates to the level of the peroneal nerve. ${ }^{140}$ Nevertheless, the biphasic dose response does not appear to be universally true. In primary microglial cell culture, a dose-dependent response to NIR was demonstrated with no detrimental effects at doses as high as $30 \mathrm{~J} / \mathrm{cm}^{2} .{ }^{141}$

So a critical question in the use of NILT is that of radiant energy penetration. In particular, some authors have challenged the efficacy of low-power LEDs used in LLLT. ${ }^{142-144}$ In laboratory studies, LLLT radiant energy is almost entirely absorbed in the first $1 \mathrm{~mm}$ of skin. ${ }^{145,146}$ In two unrelated studies, LLLT diode devices proved to be ineffective in the treatment of diabetic neuropathy, ${ }^{142,144}$ in contrast with prior reports. ${ }^{147}$ Similarly, laboratory studies of NILT using LLLT transcranially have not consistently yielded positive results. For example, in a rat model of TBI, Giacci et al ${ }^{148}$ found no benefit from daily 30-minute irradiation with either $670 \mathrm{~nm}$ or $830 \mathrm{~nm} 0.5 \mathrm{~W}$ LED emitters for a period of 7 days. Doses at the skin surface were $28.4 \mathrm{~J} / \mathrm{cm}^{2}$ and $22.6 \mathrm{~J} / \mathrm{cm}^{2}$, respectively. ${ }^{148}$ Similarly, treatment of a rat model of contusive spinal cord injury with LLLT $\left(830 \mathrm{~nm}\right.$ at $22.6 \mathrm{~J} / \mathrm{cm}^{2}$ or $670 \mathrm{~nm}$ at $28.4 \mathrm{~J} / \mathrm{cm}^{2}$ ) for 30 minutes per day for 5 days resulted in no significant functional improvement and no reduction in lesion size, despite delivering $2.6 \mathrm{~J} / \mathrm{cm}^{2}$ to the spinal cord. ${ }^{148}$

Lapchak $^{102}$ reported that the physical parameters of NILT in the clinical trials for the treatment of stroke utilized in the NEST-1 and NEST-2 trials ${ }^{116-120}$ may have delivered insufficient energy to cortical tissues to be effective. Therein, NIR light of $808 \mathrm{~nm}$ wavelength with infrared energy densities of $0.9 \mathrm{~J} / \mathrm{cm}^{2}$ was applied to the human scalp for a total of 40 minutes with applications at multiple sites during that time. ${ }^{16,118}$ Recall that animal models of both stroke and TBI suggest that NIR energy densities in the range of $0.9-36 \mathrm{~J} / \mathrm{cm}^{2}$ resulted in significant biochemical and behavioral changes. ${ }^{96,106-115,125-127}$ The concern raised from the NEST studies ${ }^{102}$ is that current clinical trials testing the effectiveness of low-energy NIR diodes to treat TBI may yield negative or inaccurate efficacy data, not because of a failure of infrared light to invoke a change but due to a dose error. Doses that are effective when directly applied to cells in a Petri $\operatorname{dish}^{149,150}$ or to 3-5 mm thick rodent brains ${ }^{96,109-111,125,126,128}$ may be insufficient to penetrate $2-4 \mathrm{~cm}$ into the human brain.

In a companion paper, our own studies of photonic energy penetration are detailed. ${ }^{105}$ To summarize, the laboratory tissue studies showed that $0.5 \mathrm{~W}$ LED emitters did not penetrate the $2 \mathrm{~mm}$ thickness of human skin. No detectable energy from 0.5 W LED NIR light emitters could be detected penetrating a similar thickness (1-2 mm) of sheep skin or $3 \mathrm{~cm}$ thick section containing sheep skin, skull, and brain. In contrast, $11 \%$ of the photonic energy from a $10 \mathrm{~W} 810 / 980 \mathrm{~nm}$ coherent NIR laser penetrated $2 \mathrm{~mm}$ of human skin. Similarly, $17 \%$ of the photonic energy from a $15 \mathrm{~W} 810 \mathrm{~nm}$ coherent NIR laser penetrated the same distance. ${ }^{105}$ Energy from these more powerful NIR emitters could be detected penetrating $3 \mathrm{~cm}$ of sheep skin, skull, and brain with $0.4 \%$ of the $10 \mathrm{~W} 810 / 980 \mathrm{~nm}$ NIR laser's energy reaching the depth of $3 \mathrm{~cm}$ and $2.9 \%$ of the $15 \mathrm{~W} 810 \mathrm{~nm}$ NIR laser's energy traversing the same distance. ${ }^{105}$ Anders also has demonstrated penetration of $808 \mathrm{~nm}$ light to $40 \mathrm{~mm}$ in the brain using a $5 \mathrm{~W}$ laser emitter (JJ Anders, personal communication, January 2015). Prompted by the mixed results in the literature and the observations by Lapchak, ${ }^{102}$ Franzen-Korzendorfer et al, ${ }^{144}$ Wan et $\mathrm{al}^{151}$ and Lavery et $\mathrm{al}^{142}$ we have been utilizing relatively high-power (10-15 W) lasers at the wavelengths of $810 \mathrm{~nm}$ and $980 \mathrm{~nm}$ in the clinic to treat patients with TBI. Clinically, the patients have shown excellent responses with resolution of many of their long-standing symptoms of TBI or post-concussive syndrome. Below is a retrospective series of such patients to illustrate the extent and character of response to this modality.

\section{Methods}

Patients in the case series were sequentially treated patients at a clinic which is engaged in ongoing NILT for a number of clinical conditions. The risks, benefits, and current state of research on the use of NILT were explained to each patient. Each patient consented to treatment. Institutional Review Board approval was obtained in a post hoc review, noting that the risk-benefit ratio was acceptable.

Between March 16, 2011 and February 20, 2013, sequential new referrals for chronic mild-to-moderate TBI were evaluated for treatment and selected for NILT using Class IV lasers, either the LT1000 (LiteCure, Newark, DE, USA), a $10 \mathrm{~W}$ adjustable NIR laser emitter with wavelengths of $810 / 980 \mathrm{~nm}$ capable of delivering continuous or pulsed NIR light, or the Diowave 810 (Diowave, Riviera Beach, FL, USA), an adjustable NIR emitter up to $15 \mathrm{~W}$ with a wavelength of $810 \mathrm{~nm}$ capable of delivering continuous or pulsed NIR energy. Demographics and laser treatment settings are detailed in Table 1. The fluence delivered to the skin of patients ranged from $55 \mathrm{~J} / \mathrm{cm}^{2}$ to $81 \mathrm{~J} / \mathrm{cm}^{2}$. No other treatment modalities (medications, exercise regimen, supplements) were added, discontinued, or changed while receiving NILT. Symptoms 
were monitored clinically. A baseline Quick Inventory of Depressive Symptomatology Self-Report (QIDS-SR) ${ }^{152}$ was completed for all patients, and the $\mathrm{BDI}^{153}$ was administered to seven of the ten patients before and after the course of treatment. In addition, each patient was instructed on how to create and maintain a patient and spousal diary of symptoms and subjective progress. Each of six patients received a single series of ten treatments with the LT1000 Class IV laser. Three additional patients each received a single series of 20 treatments with the LT1000 Class IV laser. One patient was treated with the Diowave $810 \mathrm{~nm}$ Class IV laser device in a series of 20 treatments. The patients and treating clinician wore protective eyewear. There were no incidents of burns or thermal discomfort (Figure 2).

\section{The impact of high-watt NILT}

While the patient group represented a diverse mix (Table 1 presents demographics), some notable commonalities of symptoms emerged. Over $90 \%$ of the patients had complaints of anxiety, depression, irritability, and insomnia. Other symptoms included headache $(60 \%)$, suicidal ideation (50\%), cognitive difficulties (50\%), attention problems $(50 \%)$, short-term memory problems (40\%), loss of libido (30\%), substance abuse $(20 \%)$, fatigue $(20 \%)$, and panic attacks $(20 \%)$. Six of the patients were unemployed prior to treatment. Three of the patients were experiencing severe marital difficulties. All carried or had a confirmed diagnosis of TBI, but other comorbid diagnoses included PTSD, major depressive disorder, generalized anxiety disorder, bipolar disorder, and attention deficit/hyperactivity disorder. The patients' baseline scores on the BDI were 25.3 \pm 12.1 (moderate depression range), and baseline scores on the QIDS-SR were 12.9 \pm 4.6 (moderate depression range).

During NILT treatments, skin temperature increased no more than $3^{\circ} \mathrm{C}$ with rapid cooling after removal of the NIR light. A continuous sweeping motion was utilized to minimize skin heating and cover a larger area. After a course of ten treatments of NILT (20 treatments in four patients), each patient experienced significant clinical improvement with resolution of many of their symptoms (Table 2). In addition, the BDI scores dropped to $12 \pm 6.5$ (nondepressed range). This represented a significant decrease $(P<0.01$, Student's $t$-test, one-tailed, Microsoft Excel). The QIDS-SR scores after treatment were 2.2 \pm 2.3 (nondepressed range), and the difference from baseline was highly significant $(P<0.00001$, Student's $t$-test, one-tailed). Patients noted improvement in cognitive function, mood, anxiety, and sleep. None of the patients continued to have suicidal thoughts $(50 \%$ at baseline). Other symptoms, such as anxiety and irritability, were markedly improved. Most notable were the nonquantifiable changes in patients' lives. Patients reported improved cognitive ability and a desire to return to meaningful work. Five of the six unemployed patients have returned to work. The two patients who were Iraq/Afghanistan veterans have found new careers in highly skilled trades. The patients with marital difficulties have reconciled and were purchasing homes or otherwise solidifying their marriages. The clinical change can be attributed to NILT because no changes in medications, supplements, or exercise regimen were permitted during the course of NILT treatment.

All patients in the case series experienced significant clinical improvement which supports the conjecture that high-power NIR laser delivers sufficient energy to the human brain for photobiomodulation to occur. Insomnia and suicidal ideation, common symptoms in those with TBI or post-concussive syndromes, ${ }^{3,17-20,24,25}$ resolved in $100 \%$ of cases. Headache, another common symptom for patients following a TBI, ${ }^{6,14,15,23}$ was reduced or resolved in the six patients so afflicted. Symptoms such as anxiety, ${ }^{14,15,21,24}$ depression, ${ }^{21,24,25,27-29}$ and irritability resolved or were dramatically reduced in all patients. Cognitive function appeared to improve based on return to work or improved work performance, although cognitive tests were not performed. The quality of life dramatically improved in all cases, based on the observations of the patients, their family members, and the treating clinician.

At follow-up intervals of 6-7 months posttreatment, patients have reported continued improvements in symptoms. The precise areas of brain injury were not elucidated in the majority of these cases, so a correlation of symptoms changes and cortical function changes cannot be made; however, perfusion SPECT imaging in other patients has shown significant increases in perfusion in injured areas of the brain and overall improved cortical function following similar courses of high-watt NILT. ${ }^{154}$

One concern that has been expressed about high-watt NIR lasers is the risk of tissue heating. ${ }^{155}$ We explored this issue in our companion paper on NIR penetration. ${ }^{105}$ Temperature change was $1^{\circ} \mathrm{C}-3^{\circ} \mathrm{C}$ at the skin surface using continuous-wave NIR lasers in the range of 10-15 W. Using pulsed settings, the high-powered lasers showed no significant temperature change in tissue samples. The temperature change on human skin was $1^{\circ} \mathrm{C}$ or less in the in vivo penetration studies while maintaining continuous movement of the laser probe head. ${ }^{105}$ Clinically, patients in this case series reported only slight warming of the 


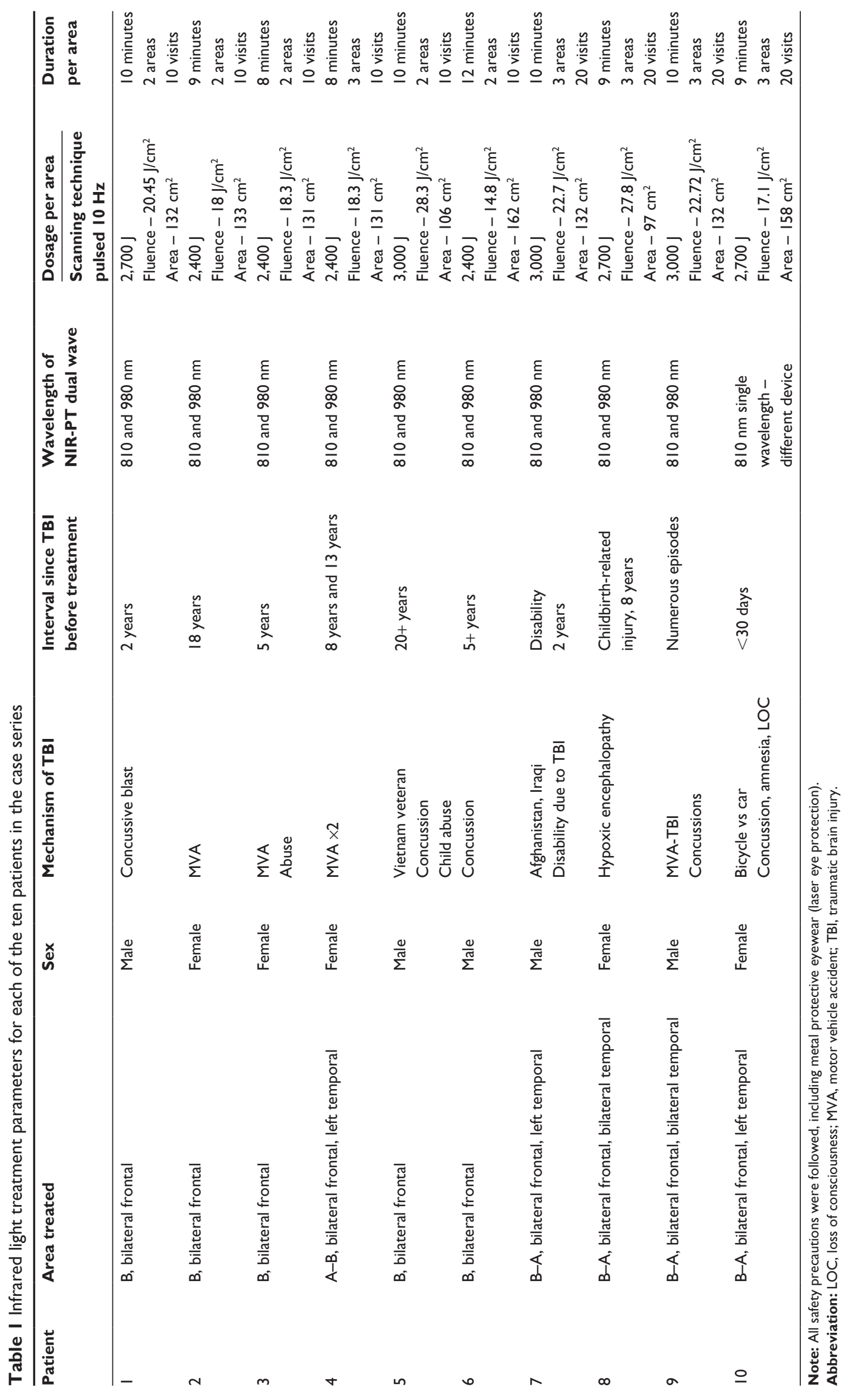




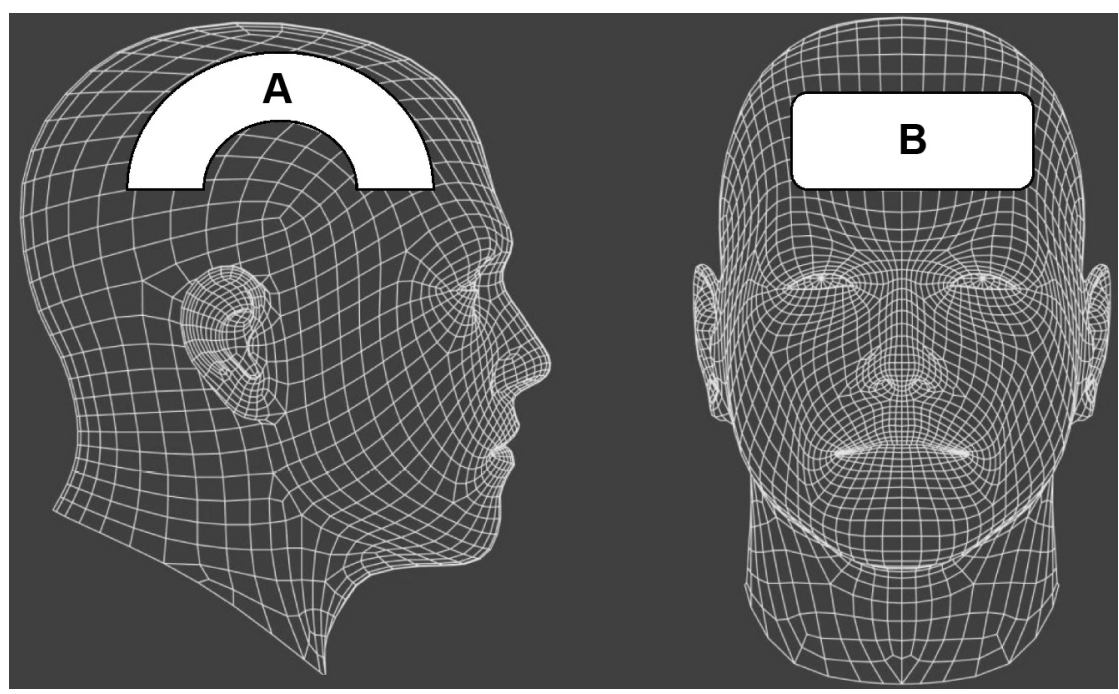

Figure 2 Treatment parameters per individual, based on area of the skull treated.

Notes: Dimensions varied per head/skull size and hair line. Treatment was warm and comfortable for each patient. There were no incidences of discomfort. Areas treated were (A) temporal-bilateral, (B) frontal, and in patients I-3, 5, and 6 (B) frontal only.

skin, but no discomfort, using the continuous motion technique.

Laboratory studies have largely focused on treatment of acute brain injury. The processes involved in the benefits of NIR light in chronic TBI as seen in this clinical case series may be quite distinct. Nevertheless, Schiffer et al ${ }^{156}$ found that a single application of LLLT at $810 \mathrm{~nm}$ and $250 \mathrm{~mW}$ to the forehead over 8 minutes reduced depression and anxiety symptoms in ten patients for approximately 2 weeks. Similarly, the small case series by Naeser et a ${ }^{103}$ demonstrated some benefit using NIR light, albeit at very low power levels over a prolonged course of several months with only transient benefit. Together with our clinical data, these findings suggest that at least some of the photobiomodulatory effects of NIR energy likely do occur in chronic neurological conditions.

Prior presentations on NILT for the treatment of TBI or stroke in humans have focused on getting photonic energy through the skull to the cortex surface which traverses a distance of about 6-10 $\mathrm{mm}$; however, this model is flawed in that the distance to the areas of damage may be far greater. In other words, the cortex immediately subjacent to a portion of the skull may be $10 \mathrm{~mm}$ from the surface, but the NIR light energy may need to penetrate 3-7 cm to reach areas of damage. Much of the cortical surface is actually lining the walls and floors of sulci, rather than immediately subjacent to the skull. Analysis of NIR spectroscopy reveals that light propagation through varying media with irregular boundaries is subject to high levels of scatter. ${ }^{157}$ In addition, review of the neuroimaging literature on TBI has revealed that the most common areas injured in TBI are the orbitofrontal cortex (at the ventral surface of the frontal lobe) and the anterior and medial temporal lobes. ${ }^{158}$ It is not anatomically possible to position an NIR light emitter immediately exterior to the skull overlying these areas. Indeed, the orbitofrontal cortex positioned immediately above the eyes can only be reached from the forehead by angling the light emitter. Similarly, the temporal lobes are separated from the surface by epidermis, dermis, subcutaneous fat, subcutaneous blood vessels, accessory head of the temporalis muscle, connective tissue, temporalis muscle, skull, and dura mater. ${ }^{159}$ Each of these structures has different absorption and refraction properties, and each interface between different materials also creates a barrier to transmission of photonic energy. ${ }^{157}$ Blood flowing in the subcutaneous vessels is believed to create a unique barrier to transmission. ${ }^{160}$ In summary, effectively targeting the areas most commonly injured in TBI with sufficient photonic energy to initiate reparative processes represents a significant challenge in NILT. This appears to have been overcome with the high-power laser protocol presented here and in a related paper. ${ }^{154}$

As yet, the mechanism of action of NILT in treating TBI is not entirely clear. Moreover, the neurological benefits are not immediately apparent. Rather, a delay of 1-4 weeks was noted, consistent with a progressive regeneration cascade set in motion by the NILT. $96,103,105,107,109,121,122,124,127,135$ Similarly, most of the patients in the present case series did not notice benefits immediately or within the first few treatments. Instead, they reported benefits emerging over an interval of weeks, and in some cases, continuing after completion of the course of NILT. In addition, the clinical improvement 


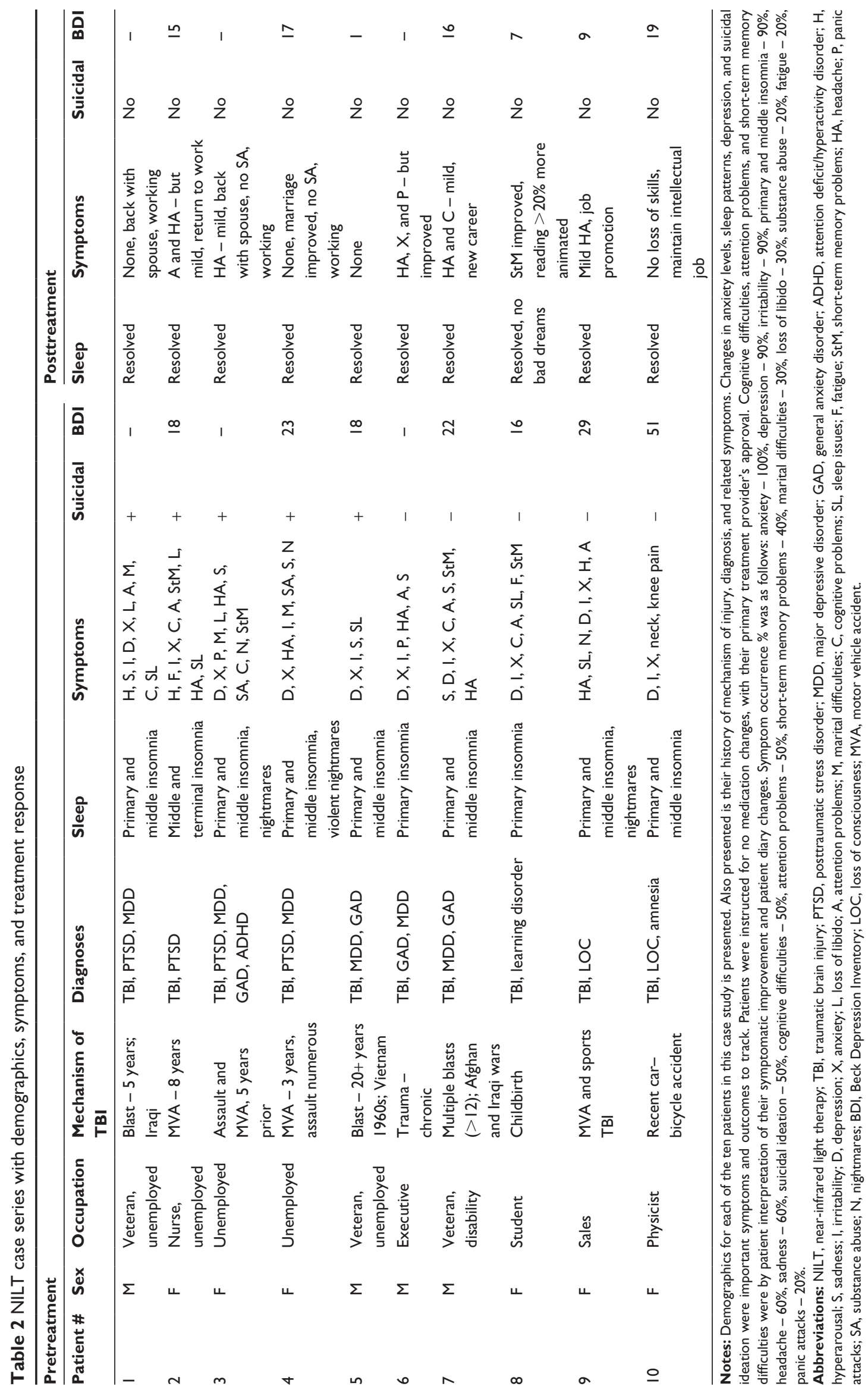


reported by the patients in the above case series is more profound than that reported by patients treated with LLLT or low-powered lasers. ${ }^{103}$ In fact, we observed that among seven subjects with documented moderate depression, per BDI scores, four had an antidepressant response $(\geq 50 \%$ decrease of depression severity). In contrast, Naeser et al ${ }^{132}$ reported that out of eight subjects with TBI and comorbid depression, only three had a significant improvement in their depressive symptoms (37.5\%). Our results may be due to the greater penetration of more powerful, coherent, and pulsed NIR light from a laser source.

A unique outcome measure was developed for this protocol (Morries and Henderson, unpublished data, 2015). A patient diary and separate spousal diary provided a weekly update of patient's response in his or her home environment. This novel approach to capturing the patient treatment experience provided the patient and family with tangible and pertinent documentation of the clinical response. While time consuming, the experiences recorded in these diaries proved to be valuable clinical tools to the treating clinicians.

\section{Conclusion}

To date, there has been little progress in developing effective treatments for chronic mild-to-moderate TBI or repetitive concussions. This area of need has become even more pressing with the return of veterans from military conflicts in Iraq and Afghanistan 4,6,76,17,19,161 and the recognition of the magnitude of sport-related TBI. ${ }^{5,8-10}$ In addition, the dramatic growth in the geriatric population with attendant proprioceptive dysfunction has resulted in a rising incidence of fall-related TBI. ${ }^{162}$

NILT has shown promise as a tool for the treatment of TBI. A critical issue is to assure that adequate photonic energy reaches the injured areas of the brain. The use of high-wattage lasers, as we have demonstrated, results in marked clinical improvement in patients with chronic TBI. Moreover, symptoms consistent with PTSD, anxiety, and/or depression also improved considerably or resolved in this group of patients. Further work in the use of high-wattage NILT in the treatment of TBI, depression, and other neurological disorders is encouraged.

\section{Acknowledgments}

The authors would like to acknowledge the technical assistance of Mr Charles Vorwaller (Diowave Corporation) and Lite Cure Corporation. The authors also acknowledge the contribution of Ms Taylor Tuteur in the artistic creation of Figure 1.

\section{Disclosure}

Dr Larry D Morries is the CEO of Neuro-Laser Foundation, a nonprofit foundation. He has a private practice in Lakewood, CO. Theodore A Henderson is the president of The Synaptic Space, a medical consulting firm. He is the president of Dr Theodore Henderson, Inc., a clinical service firm. He is the co-owner of Neuro-Luminance, a clinical service organization. He is the president of the International Society of Applied Neuroimaging. He is the CFO of the Neuro-Laser Foundation, a nonprofit foundation. Dr Paolo Cassano received funding from the Brain and Behavior Research Foundation; Photothera Inc and from the Dupont Warren Fellowship (Harvard Medical School) to conduct research on NIR light for the treatment of major depressive disorder.

\section{References}

1. Bazarian JJ, McClung J, Shah MN, Cheng YT, Flesher W, Kraus J. Mild traumatic brain injury in the United States 1998-2000. Brain Inj. 2005; 19(2):85-91.

2. Faul M, Xu L, Wald M, Coronado VG. Traumatic Brain Injury in the United States. U.S. Department of Health and Human Services Report; 2010. Available from: http://www.cdc.gov/TraumaticBrainInjury/. Accessed March 2, 2014.

3. Vaishnavi S, Rao V, Fann JR. Neuropsychiatric problems after traumatic brain injury: unraveling the silent epidemic. Psychosomatics. 2009;50(3): 198-205.

4. DOD Worldwide Numbers for TBI [webpage on the Internet]. Silver Spring, MD: Defense and Veterans Brain Injury Center; 2015. Available from: http://dvbic.dcoe.mil/dod-worldwide-numbers-tbi. Accessed January 25, 2015.

5. Bailes JE, Petraglia AL, Omalu BI, Nauman E, Talavage T. Role of subconcussion in repetitive mild traumatic brain injury. J Neurosurg. 2013;119(5):1235-1245.

6. Cifu DX, Taylor BC, Carne WF, et al. Traumatic brain injury, posttraumatic stress disorder, and pain diagnoses in OIF/OEF/OND veterans. J Rehabil Res Dev. 2014;50(9):1169-1176.

7. Logan BW, Goldman S, Zola M, Mackey A. Concussive brain injury in the military: September 2001 to the present. Behav Sci Law. 2013;31(6): 803-813.

8. Gilchrist J, Thomas KE, Xu L, McGuire LC, Coronado VG. Nonfatal sports and recreation related traumatic brain injuries among children and adolescents treated in emergency departments in the United States, 2001-2009. MMWR Morb Mortal Wkly Rep. 2011;60(39): 1337-1342.

9. Noble JM, Hesdorffer DC. Sport-related concussions: a review of epidemiology, challenges in diagnosis, and potential risk factors. Neuropsychol Rev. 2013;23(4):273-284.

10. Selassie AW, Wilson DA, Pickelsimer EE, Voronca DC, Williams NR, Edwards JC. Incidence of sport-related traumatic brain injury and risk factors of severity: a population-based epidemiologic study. Ann Epidemiol. 2013;23(12):750-756.

11. Kumar A, Loane DJ. Neuroinflammation after traumatic brain injury: opportunities for therapeutic intervention. Brain Behav Immun. 2012; 26(8):1191-1201.

12. Ziebell JM, Morganti-Kossmann MC. Involvement of pro- and antiinflammatory cytokines and chemokines in the pathophysiology of traumatic brain injury. Neurotherapeutics. 2010;7(1):22-30.

13. Anderson RJ. Shell shock: an old injury with new weapons. Mol Interv. 2008;8(5):204-218. 
14. Kashluba S, Hanks RA, Casey JE, Millis SR. Neuropsychologic and functional outcome after complicated mild traumatic brain injury. Ach Phys Med Rehabil. 2008;89(5):904-911.

15. Kennedy JE, Jaffee MS, Leskin GA, Stokes JW, Leal FO, Fitzpatrick PJ. Posttraumatic stress disorder and posttraumatic stress disorder-like symptoms and mild traumatic brain injury. J Rehabil Res Dev. 2007; 44(7):895-920.

16. Lew HL. Rehabilitation needs of an increasing population of patients: traumatic brain injury, polytrauma, and blast-related injuries. J Rehabil Res Dev. 2005;42(4):xiii-xvi.

17. Lew HL, Vanderploeg RD, Moore DF, et al. Overlap of mild TBI and mental health conditions in returning OIF/OEF service members and veterans. J Rehabil Res Dev. 2008;45(3):xi-xvi.

18. Okie S. Traumatic brain injury in the war zone. $N$ Engl J Med. 2005; 352(20):2043-2047.

19. Vasterling JJ, Proctor SP, Amoroso P, Kane R, Heeren T, Franz M. Neuropsychological outcomes of army personnel following deployment to the Iraq war. JAMA. 2006;296(5):519-529.

20. Neurobehavioral Guidelines Working Group. Guidelines for the pharmacologic treatment of neurobehavioral sequelae of traumatic brain injury. J Neurotrauma. 2006;23(10):1468-1501.

21. Fann JR, Burington B, Lenonetti A, Jaffe K, Katon WJ, Thompson RS. Psychiatric illness following traumatic brain injury in an adult health maintenance organization population. Arch Gen Psychiatry. 2004;61(1):53-61.

22. Bryan CJ. Repetitive traumatic brain injury (or concussion) increases severity of sleep disturbance among deployed military personnel. Sleep. 2013;36(6):941-946.

23. Theeler B, Lucas S, Riechers RG 2nd, Ruff RL. Post-traumatic headaches in civilians and military personnel: a comparative, clinical review. Headache. 2013;53(6):881-900.

24. Bryan CJ, Clemans TA. Repetitive traumatic brain injury, psychological symptoms, and suicide risk in a clinical sample of deployed military personnel. JAMA Psychiatry. 2013;70(7):686-691.

25. Jorge RE, Robinson RG, Moser D, Tateno A, Crespo-Facorro B, Arndt S. Major depression following traumatic brain injury. Arch Gen Psychiatry. 2004;61(1):42-50.

26. Prins ML, Alexander D, Giza CC, Hovda DA. Repeated mild traumatic brain injury: mechanisms of cerebral vulnerability. J Neurotrauma. 2013; 30(1):30-38.

27. Fann JR, Uomoto JM, Katon WJ. Sertraline in the treatment of major depression following mild traumatic brain injury. J Neuropsychiatry Clin Neurosci. 2000;12(2):226-232.

28. Fann JR, Uomoto JM, Katon WJ. Cognitive improvement with treatment of depression following mild traumatic brain injury. Psychosomatics. $2001 ; 42(1): 48-54$

29. Turner-Stokes L, Hassan N, Pierce K, Clegg F. Managing depression in brain injury rehabilitation: the use of an integrated care pathway and preliminary report of response to sertraline. Clin Rehabil. 2002;16(3): 261-268.

30. Schmitt JA, Kruizinga MJ, Riedel WJ. Non-serotonergic pharmacological profiles and associated cognitive effects of serotonin reuptake inhibitors. J Psychopharmacol. 2001;15(3):173-179.

31. Crisostomo EA, Duncan PW, Propst M, Dawson DV, Davis JN. Evidence that amphetamine with physical therapy promotes recovery of motor function in stroke patients. Ann Neurol. 1988;23(1):94-97.

32. Rau TF, Kothiwal AS, Rova AR, Brooks DM, Poulsen DJ. Treatment with low-dose methamphetamine improves behavioral and cognitive function after severe traumatic brain injury. J Trauma Acute Care Surg. 2012;73(2 suppl 1):S165-S172.

33. Johansson B, Wentzel AP, Andréll P, Odenstedt J, Mannheimer C, Rönnbäck L. Evaluation of dosage, safety and effects of methylphenidate on post-traumatic brain injury symptoms with a focus on mental fatigue and pain. Brain Inj. 2014;28(3):304-310.

34. Nickels JL, Schneider WN, Dombovy ML, Wong TM. Clinical use of amantadine in brain injury rehabilitation. Brain Inj. 1994;8(8): 709-718.
35. Kraus MF, Maki P. The combined use of amantadine and 1-dopa/ carbidopa in the treatment of chronic brain injury. Brain Inj. 1997;11(6): 455-460.

36. McDowell S, Whyte J, D'Esposito M. Differential effect of a dopaminergic agonist on prefrontal function in traumatic brain injury patients. Brain. 1998;121(pt 6):1155-1164.

37. Catsman-Berrevoets CE, von Harskamp F. Compulsive pre-sleep behavior and apathy due to bilateral thalamic stroke: response to bromocriptine. Neurology. 1988;38(4):647-649.

38. Ishizuka T, Murotani T, Yamatodani A. Modanifil activates the histaminergic system through the orexinergic neurons. Neurosci Lett. 2010; 483(3):193-196.

39. Guo RX, Anaclet C, Roberts JC, et al. Differential effects of acute and repeat dosing with the H3 antagonist GSK189254 on the sleep-wake cycle and narcoleptic episodes in Ox-/- mice. Br J Pharmacol. 2009; 157(1):104-117.

40. Scammell TE, Estabrooke IV, McCarthy MT, et al. Hypothalamic arousal regions are activated during modafinil-induced wakefulness. J Neurosci. 2000;20(22):8620-8628.

41. Kim W, Tateno A, Arakawa R, et al. In vivo activity of modafinil on dopamine transporter measured with positron emission tomography and $\left[{ }^{18} \mathrm{~F}\right] \mathrm{FE}-\mathrm{PE} 2 \mathrm{I}$. Int $J$ Neuropsychopharmacol. 2014;17(5): 697-703.

42. Wisor JP, Nishino S, Sora I, Uhl GH, Mignot E, Edgar DM. Dopaminergic role in stimulant-induced wakefulness. J Neurosci. 2001;21(5): 1787-1794.

43. Taverni JP, Seliger G, Lichtman SW. Donepezil medicated memory improvement in traumatic brain injury during post acute rehabilitation. Brain Inj. 1998;12(1):77-80.

44. Whelan FJ, Walker MS, Schultz SK. Donepezil in the treatment of cognitive dysfunction associated with traumatic brain injury. Ann Clin Psychiatry. 2000;12(3):131-135.

45. Kaye NS, Townsend JB 3rd, Ivins R. An open-label trial of donepezil (aricept) in the treatment of persons with mild traumatic brain injury. $J$ Neuropsychiatry Clin Neurosci. 2003;15(3):383-384.

46. Morey CE, Cilo M, Berry J, Cusick C. The effect of Aricept in persons with persistent memory disorder following traumatic brain injury: a pilot study. Brain Inj. 2003;17(9):809-815.

47. Silver JM, Arciniegas DB, Yodofsky S. Psychopharmacology. In: Silver JM, McAllister TW, Yodofsky S, editors. Textbook of Traumatic Brain Injury. Arlington, VA: American Psychiatric Publishing; 2005: 609-639.

48. Kemp S, Biswas R, Neumann V, Coughlan A. The value of melatonin for sleep disorders occurring post-head injury: a pilot RCT. Brain Inj. 2004;18(9):911-919.

49. Lee HB, Lyketsos CG, Rao V. Pharmacological management of the psychiatric aspects of traumatic brain injury. Int Rev Psychiatry. 2003; 15(4):359-370.

50. Cicerone KD, Dahlberg C, Kalmar K, et al. Evidence-based cognitive rehabilitation: recommendations for clinical practice. Arch Phys Med Rehabil. 2000;81(12):1596-1615

51. Park NW, Ingles JL. Effectiveness of attention rehabilitation after an acquired brain injury: a meta-analysis. Neuropsychology. 2001;15(2): 199-210.

52. Prigatano GP, Fordyce DJ, Zeiner HK, Roueche JR, Pepping M, Wood BC. Neuropsychological rehabilitation after closed head injury in young adults. J Neurol Neurosurg Psychiatry. 1984;47(5): 505-513.

53. Ben-Yishay Y, Diller L. Cognitive remediation in traumatic brain injury: update and issues. Arch Phys Med Rehabil. 1993;74(2):204-213.

54. Chung CSY, Pollock A, Campbell T, Durward BR, Hagen S. Cognitive rehabilitation for executive dysfunction in adults with stroke or other adult non-progressive acquired brain damage. Cochrane Database Syst Rev. 2013;4:CD008391

55. Soo C, Tate RL. Psychological treatment for anxiety in people with traumatic brain injury. Cochrane Database Syst Rev. 2007;3: Cd005239. 
56. Corrigan PW, Bach PA. Behavioral treatment. In: Silver JM, McAllister TW, Yodofsky S, editors. Psychopharmacology in Textbook of Traumatic Brain Injury. Arlington, VA: American Psychiatric Publishing; 2005:661-678.

57. Prins ML, Matsumoto JH. The collective therapeutic potential of cerebral ketone metabolism in traumatic brain injury. J Lipid Res. 2014; 55(12):2450-2457.

58. Diamond BJ, Shiflett SC, Feiwel N, et al. Ginkgo biloba extract: mechanisms and clinical indications. Arch Phys Med Rehabil. 2000;81(5) 668-678.

59. al-Zuhair H, Abd el-Fattah A, el-Sayed MI. The effect of meclofenoxate with ginkgo biloba extract or zinc on lipid peroxide, some free radical scavengers and the cardiovascular system of aged rats. Pharmacol Res. 1998;38(1):65-72.

60. Bacci Ballerini F, López Anguera A, Alcaraz P, Hernández Reyes N. Treatment of postconcussion syndrome with S-adenosylmethionine. Med Clin (Barc). 1983;80(4):161-164.

61. Başkaya MK, Doğan A, Rao AM, Dempsey RJ. Neuroprotective effects of citicoline on brain edema and blood-brain barrier breakdown after traumatic brain injury. J Neurosurg. 2000;92(3):448-452.

62. Zafonte RD, Bagiella E, Ansel BM, et al. Effect of citicoline on functional and cognitive status among patients with traumatic brain injury: citicoline brain injury treatment trial (COBRIT). JAMA. 2012;308(19): 1993-2000.

63. Hakkarainen H, Hakamies L. Piracetam in the treatment of postconcussional syndrome. A double-blind study. Eur Neurol. 1978;17(1): $50-55$.

64. Malykh AG, Sadaie MR. Piracetam and piracetam-like drugs: from basic science to novel clinical applications to CNS disorders. Drugs. 2010;70(3):287-312.

65. Furukawa S, Yang L, Sameshima H. Galantamine, an acetylcholinesterase inhibitor, reduces brain damage induced by hypoxia-ischemia in newborn rats. Int J Dev Neurosci. 2014;37:52-57.

66. Masliah E, Díez-Tejedor E. The pharmacology of neurotrophic treatment with cerebrolysin: brain protection and repair to counteract pathologies of acute and chronic neurological disorders. Drugs Today (Barc). 2012;48(suppl A):3-24.

67. Zhang Y, Chopp M, Meng Y, et al. Improvement in functional recovery with administration of cerebrolysin after experimental closed head injury. J Neurosurg. 2013;118(6):1343-1355.

68. Chen CC, Wei ST, Tsaia SC, Chen XX, Cho DY. Cerebrolysin enhances cognitive recovery of mild traumatic brain injury patients: double-blind, placebo-controlled, randomized study. Br J Neurosurg. 2013;27(6):803-807.

69. Hall ED, Vaishnav RA, Mustafa AG. Antioxidant therapies for traumatic brain injury. Neurotherapeutics. 2010;7(1):51-61.

70. Hukkelhoven CW, Steyerberg EW, Farace E, Habbema JD, Marshall LF, Maas AI. Regional differences in patient characteristics, case management, and outcomes in traumatic brain injury: experience from the tirilazad trials. J Neurosurg. 2002;97(3):549-557.

71. Hasadsri L, Wang BH, Lee JV, et al. Omega-3 fatty acids as a putative treatment for traumatic brain injury. J Neurotrauma. 2013; 30(11):897-906

72. Aminmansour B, Nikbakht H, Ghorbani A, et al. Comparison of the administration of progesterone versus progesterone and vitamin $\mathrm{D}$ in improvement of outcomes in patients with traumatic brain injury: a randomized clinical trial with placebo group. Adv Biomed Res. 2012;1:58

73. Scrimgeour AG, Condlin ML. Nutritional treatment for traumatic brain injury. J Neurotrauma. 2014;31(11):989-999.

74. Amen DG, Wu JC, Taylor D, Willeumier K. Reversing brain damage in former NFL players: implications for traumatic brain injury and substance abuse rehabilitation. J Psychoactive Drugs. 2011;43(1): $1-5$.

75. Theadom A, Mahon S, Barker-Collo S, et al. Enzogenol for cognitive functioning in traumatic brain injury: a pilot placebo-controlled RCT Eur J Neurol. 2013;20(8):1135-1144.
76. Pape TL, Rosenow J, Lewis G. Transcranial magnetic stimulation: a possible treatment for TBI. J Head Trauma Rehabil. 2006;21(5):437-451.

77. Couturier JL. Efficacy of rapid-rate repetitive transcranial magnetic stimulation in the treatment of depression: a systematic review and meta-analysis. J Psychiatry Neurosci. 2005;30(2):83-90.

78. Castel-Lacanal E, Tarri M, Loubinoux I, et al. Transcranial magnetic stimulation in brain injury. Ann Fr Anesth Reanim. 2014;33(2):83-87.

79. Clark JM, Lambertsen CJ, Gelfand R, et al. Effects of prolonged oxygen exposure at 1.5, 2.0, or 2.5 ATA on pulmonary function in men (predictive studies V). J Appl Physiol (1985). 1999;86(1):243-259.

80. Collet JP, Vanasse M, Marois P, et al. Hyperbaric oxygen for children with cerebral palsy: a randomised multicentre trial. HBO-CP Research Group. Lancet. 2001;357(9256):582-586.

81. James PB. Hyperbaric oxygenation for cerebral palsy. Lancet. 2001; 357:2052-2053.

82. Boussi-Gross R, Golan H, Fishlev G, et al. Hyperbaric oxygen therapy can improve post concussion syndrome years after mild traumatic brain injury - randomized prospective trial. PLoS One. 2013;8(11): e79995.

83. Harch PG, Andrews SR, Fogarty EF, et al. A phase I study of lowpressure hyperbaric oxygen therapy for blast-induced post-concussion syndrome and post-traumatic stress disorder. $J$ Neurotrauma. 2012;29:168-185.

84. Wolf G, Cifu D, Baugh L, Carne W, Profenna L. The effect of hyperbaric oxygen on symptoms after mild traumatic brain injury. J Neurotrauma. 2012;29(17):2606-2612.

85. Miller RS, Weaver LK, Bahraini N, et al. Effects of hyperbaric oxygen on symptoms and quality of life among service members with persistent postconcussion symptoms: a randomized clinical trial. JAMA Intern Med. 2015;175(1):43-52.

86. Harch PG. Hyperbaric oxygen therapy for post-concussion syndrome: contradictory conclusions from a study mischaracterized as shamcontrolled. J Neurotrauma. 2013;30(23):1995-1999.

87. Bennett MH, Trytko B, Jonker B. Hyperbaric oxygen therapy for the adjunctive treatment of traumatic brain injury. Cochrane Database Syst Rev. 2012;12:CD004609.

88. Rockswold SB, Rockswold GL, Zaun DA, et al. A prospective, randomized clinical trial to compare the effect of hyperbaric to normobaric hyperoxia on cerebral metabolism, intracranial pressure, and oxygen toxicity in severe traumatic brain injury. $J$ Neurosurg. 2010;112: 1080-1094.

89. Rockswold SB, Rockswold GL, Zaun DA, Liu J. A prospective, randomized phase II clinical trial to evaluate the effect of combined hyperbaric and normobaric hyperoxia on cerebral metabolism, intracranial pressure, oxygen toxicity, and clinical outcome in severe traumatic brain injury. J Neurosurg. 2013;118(6):1317-1328.

90. Golden ZL, Neubauer R, Golden CJ, Greene L, Marsh J, Mleko A. Improvement in cerebral metabolism in chronic brain injury after hyperbaric oxygen therapy. Int J Neurosci. 2002;112:119-131.

91. Wortzel HS, Arciniegas DB, Anderson CA, Vanderploeg RD, Brenner LA. A phase I study of low-pressure hyperbaric oxygen therapy for blast-induced post-concussion syndrome and post-traumatic stress disorder: a neuropsychiatric perspective. J Neurotrauma. 2012;29(14):2421-2424.

92. Massett L, Moseley AM, Tate R, Harmer AR. Fitness training for cardiorespiratory conditioning after traumatic brain injury. Cochrane Database Syst Rev. 2008;2:CD006123.

93. National Research Council. Cognitive Rehabilitation Therapy for Traumatic Brain Injury: Evaluating the Evidence. Washington, DC: The National Academies Press; 2011.

94. Enwemeka CS. Intricacies of dose in laser phototherapy for tissue repair and pain relief. Photomed Laser Surg. 2009;27(3):387-393.

95. Huang YY, Chen AC, Carroll JD, Hamblin MR. Biphasic dose response in low level light therapy. Dose Response. 2009;7(4):358-383.

96. Chung H, Dai T, Sharma SK, Huang YY, Carroll JD, Hamblin MR. The nuts and bolts of low-level laser (light) therapy. Ann Biomed Eng. 2012;40(2):516-533. 
97. Mester E, Mester AF, Mester A. The biomedical effects of laser application. Lasers Surg Med. 1985;5(1):31-39.

98. Bjordal JM, Couppé C, Chow RT, Tunér J, Ljunggren EA. A systematic review of low level laser therapy with location-specific doses for pain from chronic joint disorders. Aust J Physiother. 2003;49(2): $107-116$.

99. Basford JR, Sheffield CG, Harmsen WS. Laser therapy: a randomized, controlled trial of the effects of low-intensity Nd:YAG laser irradiation on musculoskeletal back pain. Arch Phys Med Rehabil. 1999;80(6): 647-652.

100. Yang $\mathrm{Z}, \mathrm{Wu} \mathrm{Y}$, Zhang $\mathrm{H}$, et al. Low-level laser irradiation alters cardiac cytokine expression following acute myocardial infarction: a potential mechanism for laser therapy. Photomed Laser Surg. 2011;29(6):391-398.

101. Tuby H, Maltz L, Oron U. Induction of autologous mesenchymal stem cells in the bone marrow by low-level laser therapy has profound beneficial effects on the infarcted rat heart. Lasers Surg Med. 2011;43(5): 401-409.

102. Lapchak PA. Taking a light approach to treating acute ischemic stroke patients: transcranial near-infrared laser therapy translational science. Ann Med. 2010;42(8):576-586.

103. Naeser MA, Saltmarche A, Krengel MA, Hamblin MR, Knight JA. Improved cognitive function after transcranial, light-emitting diode treatments in chronic, traumatic brain injury: two case reports. Photomed Laser Surg. 2011;29(5):351-358.

104. Karu TI, Kolyakov SF. Exact action spectra for cellular responses relevant to phototherapy. Photomed Laser Surg. 2005;23(4): 355-361.

105. Henderson TA, Morries LD. Near-infrared photonic energy penetrationcan infrared phototherapy effectively reach the human brain? Neuropsychiatr Dis Treat. In press 2015.

106. Wu HM, Huang SC, Vespa P, Hovda DA, Bergsneider M. Redefining the pericontusional penumbra following traumatic brain injury: evidence of deteriorating metabolic derangements based on positron emission tomography. J Neurotrauma. 2013;30(5):352-360.

107. Yip KK, Lo SC, Leung MC, So SK, Tang CY, Poon DM. The effect of low-energy laser irradiation on apoptotic factors following experimentally induced transient cerebral ischemia. Neuroscience. 2011;190: 301-306.

108. Oron A, Oron U, Chen J, et al. Low level laser therapy applied transcranially to rats after induction of stroke significantly reduces long-term neurological deficits. Stroke. 2006;37:2620-2624.

109. Oron A, Oron U, Streeter J, et al. Low-level laser therapy applied transcranially to mice following traumatic brain injury significantly reduces long-term neurological deficits. $J$ Neurotrauma. 2007;24: 651-656.

110. Wu Q, Huang YY, Dhital S, et al. Low level laser therapy for traumatic brain injury. Mechanisms for low-light therapy V. Proc SPIE. 2010; 7552:755206.

111. Ando T, Xuan W, Xu T, et al. Comparison of therapeutic effects between pulsed and continuous wave 810 -nm wavelength laser irradiation for traumatic brain injury in mice. PLoS One. 2011;6(10):e26212.

112. Leung MC, Lo SC, Siu FK, So KF. Treatment of experimentally induced transient cerebral ischemia with low energy laser inhibits nitric oxide synthase activity and up-regulates the expression of transforming growth factor-beta 1. Lasers Surg Med. 2002;31(4):283-288.

113. Detaboada L, Ilic S, Leichliter-Martha S, Oron U, Oron A, Streeter J. Transcranial application of low-energy laser irradiation improves neurological deficits in rats following acute stroke. Lasers Surg Med. 2006;38(1):70-73.

114. Lapchak PA, De Taboada L. Transcranial near infrared laser treatment (NILT) increases cortical adenosine- 5 '-triphosphate (ATP) content following embolic strokes in rabbits. Brain Res. 2010;1306: 100-105.

115. Lapchak PA, Wei J, Zivin JA. Transcranial infrared laser therapy improves clinical rating scores after embolic strokes in rabbits. Stroke. 2004;35(8):1985-1988.
116. Zivin JA, Albers GW, Bornstein N, et al. Effectiveness and safety of transcranial laser therapy for acute ischemic stroke. Stroke. 2009;40(4): 1359-1364.

117. Lampl Y, Zivin JA, Fisher M, et al. Infrared laser therapy for ischemic stroke: a new treatment strategy: results of the NeuroThera Effectiveness and Safety Trial-1 (NEST-1). Stroke. 2007;38(6):1843-1849.

118. Huisa BN, Stemer AB, Walker MG, et al. Transcranial laser therapy for acute ischemic stroke: a pooled analysis of NEST-1 and NEST-2. Int J Stroke. 2013;8(5):315-320.

119. Stemer AB, Huisa BN, Zivin JA. The evolution of transcranial laser therapy for acute ischemic stroke, including a pooled analysis of NEST-1 and NEST-2. Curr Cardiol Rep. 2010;12:29-33.

120. Hacke W, Schellinger PD, Albers GW, et al. Transcranial laser therapy in acute stroke treatment: results of neurothera effectiveness and safety trial 3, a phase III clinical end point device trial. Stroke. 2014;45(11): 3187-3193.

121. Rojas JC, Gonzalez-Lima F. Low level light therapy of the eye and brain. Eye Brain. 2011;3:49-67.

122. Fitzgerald M, Hodgetts S, Van Den Heuvel C, et al. Red/near-infrared irradiation therapy for treatment of central nervous system injuries and disorders. Rev Neurosci. 2013;24(2):205-226.

123. Rojas JC, Gonzalez-Lima F. Neurological and psychological applications of transcranial lasers and LEDs. Biochem Pharmacol. 2013; 86(4):447-457.

124. Wu Q, Xuan W, Ando T, et al. Low-level laser therapy for closed-head traumatic brain injury in mice: effect of different wavelengths. Lasers Surg Med. 2012;44:218-226.

125. Oron A, Oron U, Streeter J, et al. Near infrared transcranial laser therapy applied at various modes to mice following traumatic brain injury significantly reduces long-term neurological deficits. $J$ Neurotrauma. 2012;29(2):401-407.

126. Xuan W, Vatansever F, Huang L, et al. Transcranial low-level laser therapy improves neurological performance in traumatic brain injury in mice: effect of treatment repetition regimen. PLoS One. 2013;8(1): e53454.

127. Xuan W, Agrawal T, Huang L, Gupta GK, Hamblin MR. Low-level laser therapy for traumatic brain injury in mice increases brain derived neurotrophic factor (BDNF) and synaptogenesis. J Biophotonics. Epub 2014 Sep 8.

128. Khuman J, Zhang J, Park J, Carroll JD, Donahue C, Whalen MJ. Low-level laser light therapy improves cognitive deficits and inhibits microglial activation after controlled cortical impact in mice. $J \mathrm{Neu}$ rotrauma. 2012;29:408-417.

129. Quirk BJ, Torbey M, Buchmann E, Verma S, Whelan HT. Nearinfrared photobiomodulation in an animal model of traumatic brain injury: improvements at the behavioral and biochemical levels. Photomed Laser Surg. 2012;30(9):523-529.

130. Moreira MS, Velasco IT, Ferreira LS, et al. Effect of phototherapy with low intensity laser on local and systemic immunomodulation following focal brain damage in rat. J Photochem Photobiol B. 2009;97(3):145-151.

131. Barrett DW, Gonzalez-Lima F. Transcranial infrared laser stimulation produces beneficial cognitive and emotional effects in humans. Neuroscience. 2013;230:13-23.

132. Naeser MA, Zafonte R, Krengel MH, et al. Significant improvements in cognitive performance post-transcranial, red/near-infrared lightemitting diode treatments in chronic, mild traumatic brain injury: open-protocol study. J Neurotrauma. 2014;31(11):1008-1017.

133. Mester E, Nagylucskay S, Waidelich W, et al. [Effects of direct laser radiation on human lymphocytes]. Arch Dermatol Res. 1978;263(3): 241-245. German.

134. Kreisler M, Christoffers AB, Willershausen B, d'Hoedt B. Effect of low-level GaAlAs laser irradiation on the proliferation rate of human periodontal ligament fibroblasts: an in vitro study. J Clin Periodontol. 2003;30(4):353-358.

135. Chen AC, Arany PR, Huang YY, et al. Low-level laser therapy activates NF-kB via generation of reactive oxygen species in mouse embryonic fibroblasts. PLoS One. 2011;6(7):e22453. 
136. Demidova-Rice TN, Salomatina EV, Yaroslavsky AN, Herman IM, Hamblin MR. Low-level light stimulates excisional wound healing in mice. Lasers Surg Med. 2007;39(9):706-715.

137. Castano AP, Dai T, Yaroslavsky I, et al. Low-level laser therapy for zymosan-induced arthritis in rats: importance of illumination time. Lasers Surg Med. 2007;39(6):543-550.

138. Corazza AV, Jorge J, Kurachi C, Bagnato VS. Photobiomodulation on the angiogenesis of skin wounds in rats using different light sources. Photomed Laser Surg. 2007;25(2):102-106.

139. Desmet KD, Paz DA, Corry JJ, et al. Clinical and experimental applications of NIR-LED photobiomodulation. Photomed Laser Surg. 2006; 24(2):121-128.

140. Anders JJ, Moges H, Wu X, et al. In vitro and in vivo optimization of infrared laser treatment for injured peripheral nerves. Lasers Surg Med. 2014;46(1):34-45.

141. von Leden RE, Cooney SJ, Ferrara TM, et al. $808 \mathrm{~nm}$ wavelength light induces a dose-dependent alteration in microglial polarization and resultant microglial induced neurite growth. Lasers Surg Med. 2013;45(4):253-263.

142. Lavery LA, Murdoch DP, Williams J, Lavery DC. Does anodyne light therapy improve peripheral neuropathy in diabetes? A double-blind, sham-controlled, randomized trial to evaluate monochromatic infrared photoenergy. Diabetes Care. 2008;31(2):316-321.

143. Kolari PJ. Penetration of unfocused laser light into the skin. Arch Dermatol Res. 1985;277(4):342-344.

144. Franzen-Korzendorfer H, Blackinton M, Rone-Adams S, McCulloch J. The effect of monochromatic infrared energy on transcutaneous oxygen measurements and protective sensation: results of a controlled, double-blind, randomized clinical study. Ostomy Wound Manage. 2008;54(6):16-31.

145. Esnouf A, Wright PA, Moore JC, Ahmed S. Depth of penetration of an $850 \mathrm{~nm}$ wavelength low level laser in human skin. Acupunct Electrother Res. 2007;32(1-2):81-86.

146. Bashkatov AN, Genina EA, Kochubey VI, Tuchin VV. Optical properties of human skin, subcutaneous and mucous tissues in the wavelength range from 400 to 2,000 nm. J Phys D Appl Phys. 2005;38: 2543-2555.

147. Leonard DR, Farooqi MH, Myers S. Restoration of sensation, reduced pain, and improved balance in subjects with diabetic peripheral neuropathy: a double-blind, randomized, placebo-controlled study with monochromatic near-infrared treatment. Diabetes Care. 2004;27(1): $168-172$.

148. Giacci MK, Wheeler L, Lovett S, et al. Differential effects of 670 and $830 \mathrm{~nm}$ red near infrared irradiation therapy: a comparative study of optic nerve injury, retinal degeneration, traumatic brain and spinal cord injury. PLoS One. 2014;9(8):e104565.

149. Greco M, Vacca RA, Moro L, et al. Helium-Neon laser irradiation of hepatocytes can trigger increase of the mitochondrial membrane potential and can stimulate c-fos expression in a $\mathrm{Ca} 2+-$ dependent manner. Lasers Surg Med. 2001;29(5):433-441.
150. Frank S, Oliver L, Lebreton-De CC, et al. Infrared radiation affects the mitochondrial pathway of apoptosis in human fibroblasts. J Invest Dermatol. 2004;123(5):823-831.

151. Wan S, Parrish JA, Anderson RR, Madden M. Transmittance of nonionizing radiation in human tissues. Photochem Photobiol. 1981;34(6): 679-681.

152. Rush AJ, Trivedi MH, Ibrahim HM, et al. The 16-item quick inventory of depressive symptomatology (QIDS), clinician rating (QIDS-C), and self-report (QIDS-SR): a psychometric evaluation in patients with chronic major depression. Biol Psychiatry. 2003;54(5):573-583.

153. Homaifar BY, Brenner LA, Gutierrez PM, et al. Sensitivity and specificity of the beck depression inventory-II in persons with traumatic brain injury. Arch Phys Med Rehabil. 2009;90(4):652-656.

154. Henderson TA, Morries LD. SPECT perfusion imaging demonstrates improvement of TBI with transcranial near-infrared laser phototherapy. Adv Mind Body Med. In press 2015.

155. Joensen J, Demmink JH, Johnson MI, Iversen VV, Lopes-Martins RÁ, Bjordal JM. The thermal effects of therapeutic lasers with 810 and $904 \mathrm{~nm}$ wavelengths on human skin. Photomed Laser Surg. 2011; 29(3):145-153.

156. Schiffer F, Johnston AL, Ravichandran C, et al. Psychological benefits 2 and 4 weeks after a single treatment with near infrared light to the forehead: a pilot study of 10 patients with major depression and anxiety. Behav Brain Funct. 2009;5:46.

157. Strangman GE, Li Z, Zhang Q. Depth sensitivity and source-detector separations for near infrared spectroscopy based on the Colin27 brain template. PLoS One. 2013;8(8):e66319.

158. Raji CA, Tarzwell R, Pavel D, et al. Clinical utility of SPECT neuroimaging in the diagnosis and treatment of traumatic brain injury: a systematic review. PLoS One. 2014;9(3):e91088.

159. Clemente C. Anatomy - A Regional Atlas of the Human Body. 2nd ed. Baltimore: Urban \& Schwarzenburg Inc.; 1981.

160. Jagdeo JR, Adams LE, Brody NI, Siegel DM. Transcranial red and near infrared light transmission in a cadaveric model. PLoS One. 2012; 7(10):e47460.

161. Lange RT, Brickell TA, Ivins B, Vanderploeg RD, French LM. Variable, not always persistent, postconcussion symptoms after mild TBI in U.S. military service members: a five-year cross-sectional outcome study. J Neurotrauma. 2013;30(11):958-969.

162. Coronado VG, Thomas KE, Sattin RW, Johnson RL. The CDC traumatic brain injury surveillance system: characteristics of persons aged 65 years and older hospitalized with a TBI. $J$ Head Trauma Rehabil. 2005;20(3):215-228.
Neuropsychiatric Disease and Treatment

\section{Publish your work in this journal}

Neuropsychiatric Disease and Treatment is an international, peerreviewed journal of clinical therapeutics and pharmacology focusing on concise rapid reporting of clinical or pre-clinical studies on a range of neuropsychiatric and neurological disorders. This journal is indexed on PubMed Central, the 'PsycINFO' database and CAS,

\section{Dovepress}

and is the official journal of The International Neuropsychiatric Association (INA). The manuscript management system is completely online and includes a very quick and fair peer-review system, which is all easy to use. Visit http://www.dovepress.com/testimonials.php to read real quotes from published authors. 